\title{
Activation of group I metabotropic glutamate receptors reduces neuronal apoptosis but increases necrotic cell death in vitro
}

\author{
JW Allen ${ }^{1,2}$, SM Knoblach ${ }^{1,3}$ and Al Faden*,1,3,4 \\ 1 Institute for Cognitive and Computational Sciences, Georgetown University \\ Medical Center, Washington, DC 20007, USA \\ 2 Interdisciplinary Program in Neuroscience, Georgetown University Medical \\ Center, Washington, DC 20007, USA \\ ${ }^{3}$ Department of Neuroscience, Georgetown University Medical Center, \\ Washington, DC 20007, USA \\ ${ }^{4}$ Department of Pharmacology, Georgetown University Medical Center, \\ Washington, DC 20007, USA \\ * Corresponding author: Al Faden, EP-04 Research Building, 3970 Reservoir \\ Road, N.W. Washington, DC 20007, USA. Tel: (202) 687 0492; Fax: (202) 687 \\ 0617; E-mail: fadena@giccs.georgetown.edu
}

Received 23.7.99; revised 19.1.00; accepted 7.2.00

Edited by FD Miller

\begin{abstract}
Glutamate released during acute CNS insults acts at metabotropic glutamate receptors (mGluR), including group I mGluR. Blockade of group I mGluR during in vitro neuronal trauma provides neuroprotection, whereas activation exacerbates such injury. However, the effects of group I mGluR agonists or antagonists have been primarily studied in in vitro models characterized by necrotic cell death. We examined the role of group I mGluR in the modulation of neuronal injury induced during oxygen-glucose deprivation (OGD), a wellstudied model of necrosis, and by application of two well established pro-apoptotic agents: staurosporine and etoposide. Inhibition of group I mGluR attenuated necrosis induced by OGD, whereas selective activation of group I mGluR exacerbated such injury. In contrast, activation of group I mGluR, including selective activation of mGluR5, significantly attenuated apoptotic cell death induced by both staurosporine and etoposide. This effect was completely reversed by coapplication of a group I mGluR antagonist. Thus, group I mGluR appear to exhibit opposite effects on necrotic and apoptotic neuronal cell death. Our findings suggest that activation of mGluR1 exacerbates neuronal necrosis whereas both mGluR1 and mGluR5 play a role in attenuation of neuronal apoptosis. Cell Death and Differentiation (2000) 7, $470-476$.
\end{abstract}

Keywords: metabotropic glutamate receptor; apoptosis; necrosis; neuronal death

Abbreviations: 4CPG, (S)-4-carboxyphenylglycine; AIDA, (R,S)1-aminoindan-1, 5-dicarboxylic acid; CHPG, (R,S)-2-chloro-5- hydroxyphenylglycine; DHPG, dihydroxyphenylglycine; MK801, dizocilpine; LDH, lactate dehydrogenase; MCPG, -methyl-4carboxyphenylglycine; mGluR, metabotropic glutamate receptors; OGD, oxygen-glucose deprivation; TBI, traumatic brain injury

\section{Introduction}

Activation of both ionotropic and metabotropic glutamate receptors has been implicated in the pathophysiology of stroke and CNS trauma. It has been well established that blockade of ionotropic glutamate receptors provides neuroprotection in vitro and in vivo. ${ }^{1-5}$ Recent studies have suggested that metabotropic glutamate receptors (mGluR) are also activated following traumatic brain injury $(\mathrm{TBI})^{6-9}$ or cerebral ischemia, ${ }^{10}$ or in vitro neuronal trauma ${ }^{7,9}$ or ischemia, ${ }^{11,12}$ leading to neuroprotection or exacerbation depending upon the mGluR subtype activated.

MGluR have been divided into three groups, based on sequence homology and signal transduction mechanisms. Group I receptors (mGluR1, mGluR5) stimulate phospholipase $\mathrm{C}$, leading to phosphoinositide hydrolysis and intracellular $\mathrm{Ca}^{2+}$ mobilization; group II and group III receptors are negatively coupled to adenylyl cyclase activity, but differ in their pharmacological properties. ${ }^{13}$

Selective activation of group I mGluR potentiates NMDAinduced neuronal death in cultured neurons, ${ }^{12,14}$ and exacerbates in vitro trauma ${ }^{5,7}$ and oxygen-glucose deprivation (OGD). ${ }^{11,12}$ Inhibition of group I mGluR provides neuroprotection against in vitro trauma, ${ }^{5,7}$ and may protect against OGD. ${ }^{12}$ Moreover, group I mGluR blockade is also protective against CNS insults in vivo. ${ }^{6,7,10}$

Few studies have examined the effects of group I mGluR modulation on apoptotic cell death. Copani et al. reported that activation of group I mGluR protects against apoptosis of cerebellar granule cells grown in medium containing low levels of potassium, ${ }^{15,16}$ or cerebellar granule cells incubated with $\beta$-amyloid. ${ }^{17}$ However, the latter study used either non-selective agents or compounds with actions at multiple mGluR subtypes. More recently, activation of group I mGluR has been demonstrated to protect against apoptotic cell death and to decrease caspase-3 activity induced by nitric oxide treatment. $^{18,19}$

Because of the importance of glutamate in the pathogenesis of acute CNS injury and the fact that both apoptotic and necrotic cell death occur after such insults, we examined the effects of selective group I mGluR activation or inhibition in models demonstrating either predominantly necrotic or apoptotic cell death. OGD of rat cortical neuronal-glial cultures was used as a model of neuronal necrosis. ${ }^{12}$ Chronic application of staurosporine 
or etoposide to rat cortical neuronal-glial cultures was used to induce selective neuronal apoptosis. ${ }^{20}$

\section{Results}

\section{Effects of group I mGluR on necrotic injury}

Rat neuronal-glial cultures (17-19 DIV) were subjected to brief (30-110 min) OGD followed by oxygen and glucose replacement. Cell death was estimated by LDH release assay $24 \mathrm{~h}$ after injury. Increasing length of exposure to OGD conditions produced a progressive rise in neuronal injury, with 60 min of OGD inducing $50 \%$ neuronal death and 90 min of OGD producing nearly complete neuronal death (Figure 1). Consistent with a glutamate-mediated necrotic injury, pretreatment of neuronal-glial cultures with MK801 $(10 \mu \mathrm{M})$ produced nearly complete neuroprotection at 60,75 , and 90 min OGD. After 90 min of OGD, detectable neuronal injury occurred even in the presence of MK801 (Figure 1).

Using $60 \mathrm{~min}$ of OGD as a model of necrotic neuronal death, ${ }^{21}$ we investigated the effect of selective group I mGluR activation or inhibition. Administration of the group I mGluR antagonists MCPG $(500 \mu \mathrm{M})$, AIDA $(200 \mu \mathrm{M})$, or 4CPG $(30 \mu \mathrm{M})$ elicited significant neuroprotection against OGD-induced LDH release at $24 \mathrm{~h}$ post-injury (Figure $2 \mathrm{~A}$ ). The effects of the individual group I mGluR antagonists were not statistically different from one another. Application of AIDA $(200 \mu \mathrm{M})$ immediately following $60 \mathrm{~min}$ OGD also provided significant neuroprotection (AIDA $66 \pm 14$ versus OGD $100 \pm 13, n=31, P<0.05$, Student's $t$-test). In contrast to the neuroprotective effects of group I mGluR inhibition, the selective group I agonist DHPG $(20 \mu \mathrm{M})$ induced



Figure 1 Oxygen-glucose deprivation (OGD) induces progressive neuronal death. Rat neuronal-glial cultures were subjected to increasing duration of OGD and cell death was estimated after $24 \mathrm{~h}$ by measurement of LDH released into the media as described in Materials and Methods. Complete neuronal death in control cultures was determined by application of $200 \mu \mathrm{M}$ NMDA for $24 \mathrm{~h}$ (dotted line). Complete neuronal death was apparent after $90 \mathrm{~min}$ exposure to OGD conditions in the absence of treatment (black diamonds). MK801 produced nearly complete attenuation of cell death induced by up to $90 \mathrm{~min}$ OGD conditions (gray squares). After $90 \mathrm{~min}$ of exposure to OGD conditions, cell death was apparent even in those cultures treated with MK801. Values represent mean \pm S.E.M., $n=32$ cultures per condition. Data expressed as a percentage of NMDA-induced LDH release significant exacerbation of cell death after OGD (Figure 2B).

\section{Effects of group I mGluR on apoptosis induced by etoposide and staurosporine}

Treatment of neuronal-glial cultures with staurosporine, a nonselective protein kinase inhibitor, for $24 \mathrm{~h}$ at a concentration of $0.3 \mu \mathrm{M}$, which produces neuronal apoptosis with little glial damage ${ }^{20}$ induces a qualitative increase in the number of cells exhibiting apoptotic-like nuclear morphology after staining with Hoechst 33258 (Figure 3). Quantitatively, staurosporine induces approximately $73 \pm 6 \%$ neuronal cell death at $24 \mathrm{~h}$ as determined by LDH release following total neuronal death in sister neuronal-glial cultures treated with $200 \mu \mathrm{M}$ NMDA for $24 \mathrm{~h}(n=16)$. Qualitative increases in the
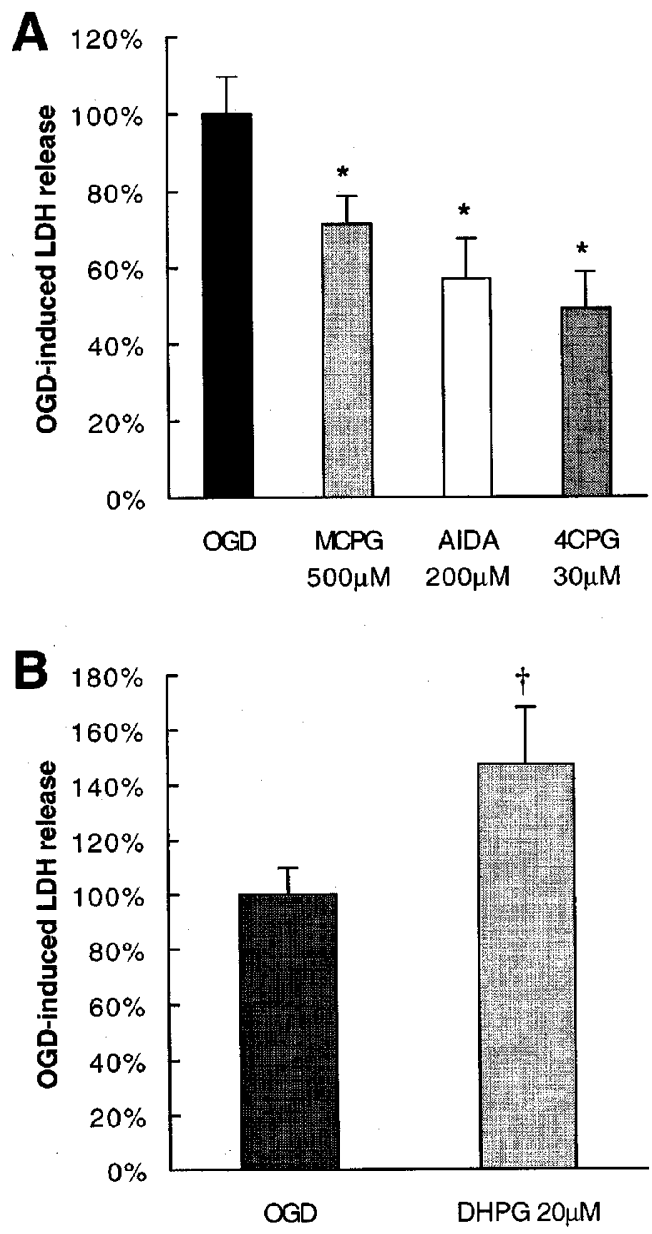

Figure 2 Inhibition of group I mGluR protects against OGD, whereas activation of group I mGluR exacerbates this injury. (A) Pre-and posttreatment with the group I/II mGluR antagonist MCPG (light gray bar), selective group I mGluR antagonist AIDA (white bar), or group I mGluR antagonist and group II mGluR agonist 4CPG (dark gray bar) significantly decreased LDH release at $24 \mathrm{~h}$ induced by 60 min OGD (black bar). (B) Selective pre- and post-injury activation of group I mGluR by DHPG (dark gray bar) significantly exacerbated $60 \mathrm{~min}$ OGD (black bar). Bars represent mean \pm S.E.M., $n=30-32$ cultures per condition. Data expressed as a percentage of OGD-induced $\mathrm{LDH}$ release. ${ }^{*} P<0.05$ vs OGD (ANOVA followed by Student-Newman-Keuls test); $\uparrow P<0.05$ vs OGD (Student's $t$-test) 

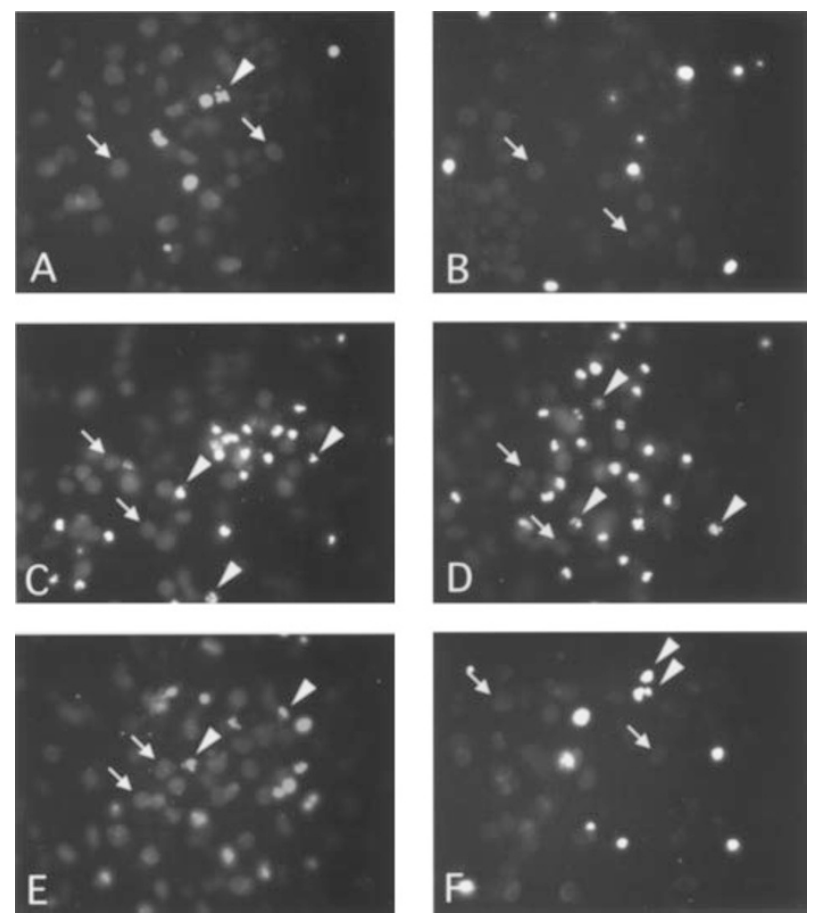

Figure 3 Staurosporine and etoposide induce nuclear condensation and fragmentation consistent with apoptotic cell death. A small number of cells exhibited condensed or fragmented in nuclei neuronal-glial cultures $24 \mathrm{~h}$ after addition of vehicle $(\mathbf{A}, \mathbf{B})$. A qualitative increase in the number of cells displaying condensed or fragmented nuclei was observed after $24 \mathrm{~h}$ incubation with staurosporine $(0.3 \mu \mathrm{M})(C)$ or etoposide $(2.5 \mu \mathrm{M})$ (D) compared with vehicle controls. A qualitative decrease in the number of the condensed or fragmented nuclei was seen after the application of DHPG $(20 \mu \mathrm{M})$ to neuronal-glial cultures treated with staurosporine $(\mathbf{E})$ or etoposide $(\mathbf{F})$. Viable neurons (arrows) exhibit diffuse nuclear staining whereas apoptotic neurons (arrowheads) are characterized by condensed and fragmented nuclei after staining with Hoechst 33258. Images were obtained at $600 \times$ after staining with Hoechst 33258 to visualize nuclear morphology as detailed in Materials and Methods

number of cells exhibiting nuclear condensation or fragmentation occurs after treatment for $24 \mathrm{~h}$ with $2.5 \mu \mathrm{M}$ etoposide, an inhibitor of topoisomerase II (Figure 3). Similar to staurosporine, this concentration of etoposide induces $77 \pm 3 \%$ neuronal death by $24 \mathrm{~h}(n=16-21)$.

Staurosporine and etoposide treatment were used as models of apoptotic neuronal injury in which to study the effects of selective group I mGluR activation or inhibition. Incubation of neuronal-glial cultures with DHPG (20$100 \mu \mathrm{M})$ significantly attenuated both staurosporine- and etoposide-induced increases in LDH release (Figure 4). Apoptosis induced by staurosporine or etoposide was insensitive to AIDA $(200 \mu \mathrm{M})$ treatment (Figure 4). However, co-administration of AIDA with DHPG completely reversed the neuroprotective effects of DHPG (Figure 4). A qualitative decrease in the number of cells with apoptoticlike morphology was also observed after treatment with DHPG in the presence of staurosporine or etoposide (Figure 3). This decrease was confirmed by quantitative counts of the number of cells containing fragmented or condensed nuclei following Hoechst 33258 (Figure 5).

The neuroprotective effects of group I mGluR activation were confirmed using a second agonist, CHPG, that is
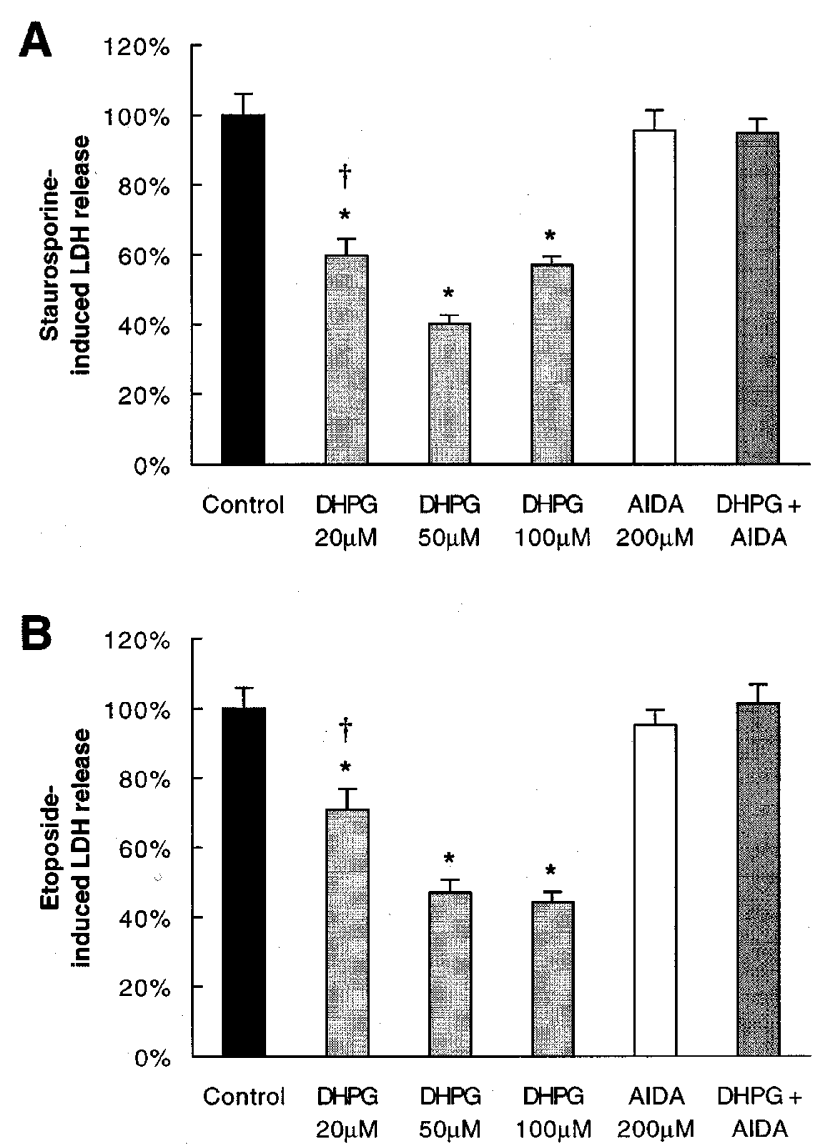

Figure 4 Activation of group I mGluR protects against staurosporine- and etoposide-induced cell death. (A) Application of the group I mGluR agonist DHPG at three doses significantly attenuated $\mathrm{LDH}$ release at $24 \mathrm{~h}$ induced by staurosporine $(0.3 \mu \mathrm{M})$. In contrast, the group I mGluR antagonist AIDA was without effect on this injury but co-application of AIDA $(200 \mu \mathrm{M})$ with DHPG $(20 \mu \mathrm{M})$ completely reversed the protective effects of group I mGluR activation. (B) Administration of DHPG $(20-100 \mu \mathrm{M})$ also significantly protected against cell death at $24 \mathrm{~h}$ induced by etoposide $(2.5 \mu \mathrm{M})$. Analogous to the lack of effect of AIDA in staurosporine-induced injury, AIDA had no effect on this injury, but completely reversed the protective effects of DHPG $(20 \mu \mathrm{M})$ when administered simultaneously. Combined treatment with a group I mGluR agonist and antagonist was performed using $20 \mu \mathrm{M}$ DHPG and $200 \mu$ M AIDA. Bars represent mean \pm S.E.M., $n=23-53$ cultures per condition. Data expressed as a percentage of staurosporine- $(\mathbf{A})$ or etoposide-induced (B) $\mathrm{LDH}$ release. ${ }^{*} P<0.05$ vs staurosporine $(\mathbf{A})$ or etoposide $(\mathbf{B})$ treatment; $\uparrow P<0.05$ vs AIDA+DHPG (ANOVA followed by Student-Newman-Keuls test)

reported to be specific for the group I mGluR mGluR5 subtype. ${ }^{22}$ Protection against staurosporine- and etoposideinduced increases in LDH release was observed after administration of $20 \mu \mathrm{M} \mathrm{CHPG} \mathrm{(Figure} \mathrm{6).}$

\section{Discussion}

Our data support the hypothesis that the effects of group I mGluR activation during neuronal injury are dependent upon the type of cell death. Inhibition of group I mGluR with a variety of antagonists attenuates necrosis induced by OGD, whereas selective activation of group I mGluR by the group I agonist DHPG exacerbates such injury. In contrast, DHPG significantly attenuates apoptotic cell death induced by both 
A

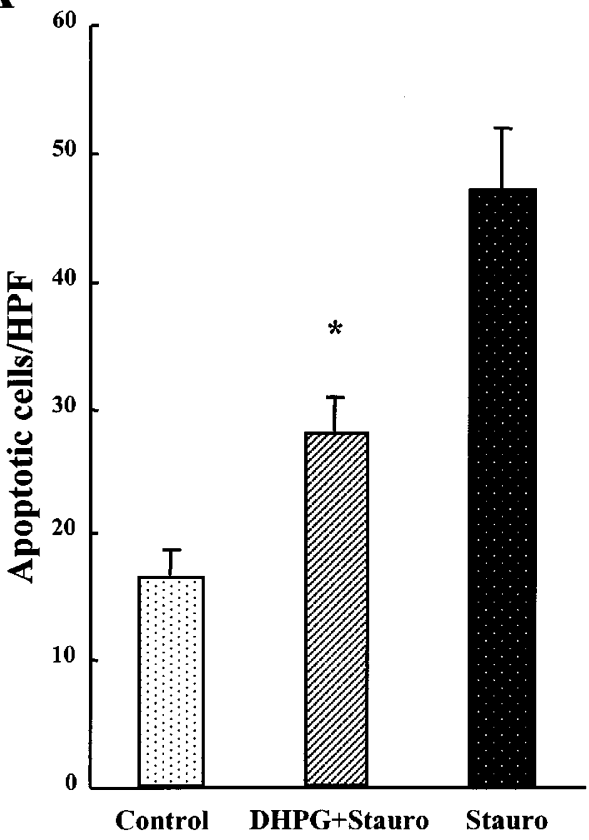

B

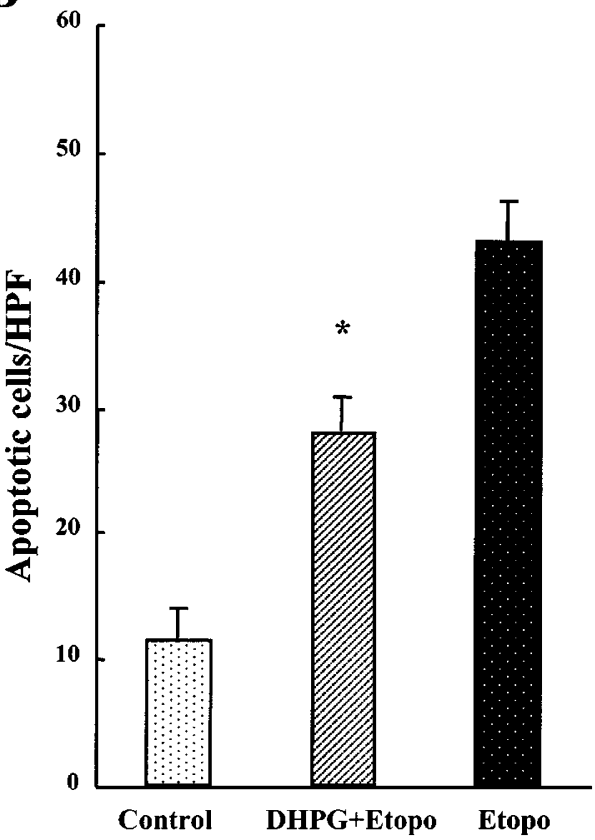

Figure 5 Group I mGluR activation elicits significant reduction in the number of apoptotic cells following staurosporine or etoposide treatment. (A) Staurosporineinduced increases in cells containing condensed or fragmented nuclei stained by Hoechst 33258 is significantly attenuated by application of DHPG (50 $\mu$ M). (B) Similarly, DHPG $(50 \mu \mathrm{M})$ also reduces the number of apoptotic cells counted after etoposide treatment. Cell counts were performed at $400 \times$ by selecting a random field as detailed in Materials and Methods. Bars represent mean + S.E.M., $n=5-11$ cultures per condition. ${ }^{*} P<0.05$ vs staurosporine (A) or etoposide (B) treatment (ANOVA followed by Student-Newman-Keuls test). HPF=high power field

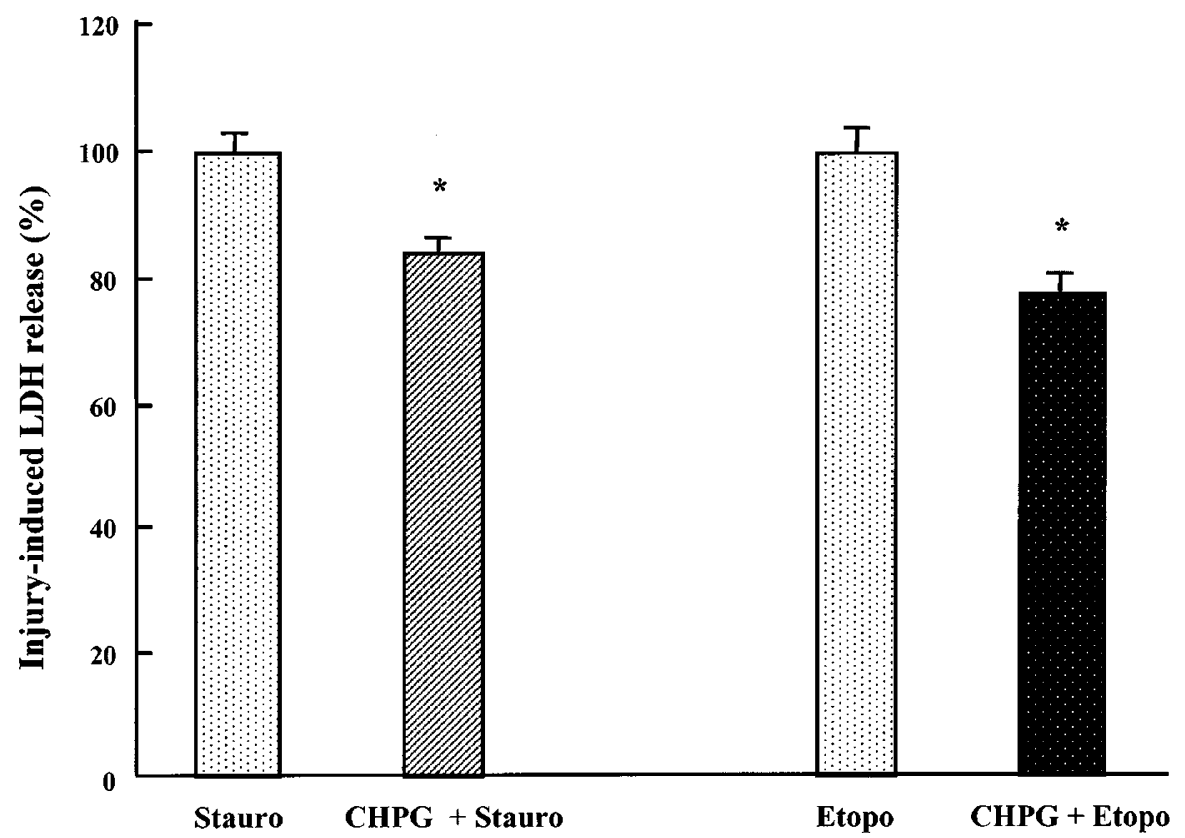

Figure 6 Selective activation of mGluR5 protects against staurosporine- or etoposide-induced cell death. Application of CHPG $(20 \mu \mathrm{M})$ during treatment with staurosporine (Stauro) or etoposide (Etopo) significantly reduces LDH release at $24 \mathrm{~h}$. Bars represent mean \pm S.E.M., $n=21-24$ cultures per condition. Data expressed as a percentage of staurosporine- or etoposide-induced LDH release. ${ }^{*} P<0.001$ vs staurosporine or etoposide treatment (Student's $t$-test)

staurosporine and etoposide. This effect is completely reversed by co-application of the group I mGluR antagonist AIDA.
The pharmacologic profiles of the agents used to modulate group I mGluR in this study have been previously reported. Three group I mGluR antagonists 
were tested in OGD-mediated injury. MCPG is an antagonist at both group I and II mGluR. ${ }^{23} 4 \mathrm{CPG}$ is an antagonist at group I mGluR and an agonist at group II mGluR. $^{23}$ AIDA is a selective antagonist at group I mGluR, ${ }^{24}$ with more activity at mGluR1 than mGluR5. ${ }^{25}$ DHPG has been reported to be a selective agonist of group I mGluR, with little or no effect on the other mGluR subtypes or ionotropic glutamate receptors studied. ${ }^{26,27}$ CHPG selectively activates the mGluR5 subtype of group I mGluR with no reported activity at mGluR1.22

A previous study using non-selective group I mGluR agonists suggested that activation of group I mGluR exacerbates OGD. ${ }^{12}$ However, the selective effects of group I mGluR inhibition in vitro have not been reported. Consistent with the work of Choi and colleagues, ${ }^{12}$ activation of group I mGluR by DHPG exacerbates OGD in our cultures. Moreover, similar to the effects on traumatic injury in vitro, ${ }^{28}$ AIDA-mediated group I mGluR inhibition significantly protected against cell death induced by OGD.

Modulation of group I mGluR may affect necrotic injury through a variety of mechanisms. Although activation of group I mGluR has been primarily associated with activation of phospholipase $\mathrm{C}$, leading to phosphoinositide hydrolysis and mobilization of intracellular calcium by inositol triphosphate and activation of protein kinase $\mathrm{C}$ (PKC) by diacylglycerol, group I mGluR activation has also been associated with increases in cyclic AMP, liberation of arachidonic acid, potentiation of NMDA receptors, and complex modulation of potassium and calcium channels. ${ }^{13}$ We have previously demonstrated that whereas antisense directed against mGluR1 or mGluR5 equally reduced group I mGluR-mediated increases in inositol phosphate accumulation, only antisense against mGluR1 significantly attenuated traumatic neuronal injury in vitro, a model of neuronal necrotic cell death. ${ }^{7}$ Therefore, increases in inositol triphosphate with resulting mobilization of intracellular calcium may not mediate group I mGluR-induced exacerbation of necrotic injury. In addition, we have previously shown in the same model that group I mGluR-mediated exacerbation occurs in the presence of NMDA receptor blockade, suggesting that potentiation of NMDA receptors is not the sole mechanism whereby group I mGluR worsen necrotic cell death. ${ }^{28}$ It remains to be determined whether activation of PKC, increases in CAMP, liberation of arachidonic acid, or modulation of calcium or potassium channels play a role in group I mGluR-mediated effects on necrotic injury.

In contrast to the exacerbating effect of group I mGluR activation on necrotic cell death, DHPG protected against well-characterized models of apoptosis induced by staurosporine and etoposide. This effect appears to be due to direct activation of group I mGluR, as co-application of AIDA completely reversed DHPG-mediated neuroprotection. Treatment with AIDA alone had no effect on either staurosporine- or etoposide-induced cell death. This is unlikely to be secondary to insufficient inhibition of group mGluR as the doses of DHPG and AIDA used in all experiments were at least twice the reported $\mathrm{EC}_{50}$ values for these compounds. ${ }^{13,24}$ Such concentrations were also shown to be maximally effective in mechanical traumatic injury using similar neuronal-glial cultures. ${ }^{7,28}$ Furthermore, this concentration of AIDA significantly exacerbates neuronal apoptosis induced by $\beta$-amyloid. ${ }^{29}$

While activation of group I mGluR may exacerbate necrotic cell death through modulation of the mGluR1 subtype as discussed above, neuroprotection produced by group I mGluR activation in the setting of apoptotic injuries is at least in part mediated via mGluR5. CHPG is a selective agonist at mGluR5 subtype with no reported agonist action at mGluR1.22 Similar to DHPG, this compound protects against both staurosporine and etoposide. Therefore, such protection against apoptosis may be mediated by mGluR5 activation. However, as AIDA completely reversed the neuroprotective effects of DHPG, and this compound is more selective for mGluR1 than for mGluR5, it is likely that both group I mGluR subtypes participate in the modulation of apoptosis.

The protective effects of DHPG against staurosporine- or etoposide-induced apoptosis may result from the ability of group I mGluR agonists to increase intracellular calcium levels. ${ }^{30,31}$ Although staurosporine does not alter intracellular calcium levels, raising intracellular calcium protects against staurosporine-induced neuronal apoptosis. ${ }^{20}$ Moreover, decreasing intracellular calcium levels potentiates apoptosis in other in vitro systems. ${ }^{32,33}$ Therefore, group I mGluR activation may protect against apoptosis by increasing release of calcium from intracellular stores or through potentiation of calcium channel activation. ${ }^{34}$

The opposite effects of group I mGluR modulation on necrosis and apoptosis presented here may have relevance for the possible therapeutic potential of group I mGluR antagonists in the treatment of CNS injury. Further studies using in vivo models of apoptosis and necrosis are warranted to determine if the differential effects of group I mGluR are also present in vivo. If inhibition of group I mGluR increases apoptotic cell death after in vivo injury, these findings suggest that the effectiveness of group I mGluR antagonists in CNS trauma and ischemia may be substantially enhanced by simultaneously blocking apoptosis.

\section{Materials and Methods}

\section{Tissue culture}

Glia were prepared from 1-3-day-old Sprague-Dawley rat cortices (Taconic Farms, Germantown, NY, USA) and neurons were prepared from 18-day-old Sprague-Dawley rat embryonic cortices as previously described in detail. ${ }^{35}$ Briefly, dissociated cortices from 1-3-day-old rats were seeded in 96-well Primaria microplates (Falcon, Lincoln Park, NJ, USA) and were allowed to grow to confluency. Isolated embryonic cortices were dissociated and individual cells $\left(2-2.5 \times 10^{6}\right.$ cells $/ \mathrm{ml}$ ) were seeded on 10-day-old in vitro (DIV) confluent glial cultures. Cortices were dissociated in Hank's balanced salt solution without calcium or magnesium (Mediatech, Herndon, VA, USA) supplemented with $10 \mathrm{mM}$ HEPES ( $\mathrm{pH}$ 7.0; Biofluids, Rockville, MD, USA) and $1 \mathrm{mM}$ sodium pyruvate (Biofluids). Cultures were fed twice per week by replacement of one-third of media with minimal essential medium with Earle's salts (Mediatech) supplemented with $10 \%$ equine serum (HyClone Laboratories, Logan, UT, USA), 27.5 mM HEPES (pH 
7.2), $2 \mathrm{mM}$ glutamine (Biofluids), $20 \mathrm{mM}$ glucose (Biofluids), and $1 \%$ antibiotic-antimycotic solution (Biofluids). Ara-C (10 $\mu \mathrm{M}$; Sigma, St. Louis, MO, USA) was added during the first feeding to stop further glial proliferation. After $10 \mathrm{DIV}$, glutamine concentration was reduced to $1 \mathrm{mM}$ and equine serum was omitted. Cultures were incubated at $37^{\circ} \mathrm{C}$ in humid atmosphere with $4 \% \mathrm{CO}_{2}$. Neuronal-glial cultures were used at 19-21 DIV.

\section{Induction of oxygen-glucose deprivation (OGD) injury}

Neuronal-glial cultures 17-20 DIV were used for OGD experiments. Atmosphere was evacuated from Anaerobic System Model 1025 (Forma Scientific, Marietta, OH, USA) and replaced with $5 \% \mathrm{CO}_{2}, 10 \%$ $\mathrm{H}_{2}$, and $85 \% \mathrm{~N}_{2}$. Remaining $\mathrm{O}_{2}$ was scavenged by a palladium catalyst (Forma Scientific). Deoxygenated balanced salt solution (BSS; $116 \mathrm{mM} \mathrm{NaCl}, 5.4 \mathrm{mM} \mathrm{KCl}, 0.8 \mathrm{mM} \mathrm{MgSO}_{4}, 1.8 \mathrm{mM} \mathrm{CaCl}_{2}$, $1.0 \mathrm{mM} \mathrm{NaH}_{2} \mathrm{PO}_{4}, 26.2 \mathrm{mM} \mathrm{NaHCO}_{3}, 0.01 \mathrm{mM}$ glycine, and $10 \mathrm{mg} / \mathrm{L}$ phenol red) was prepared by bubbling with the anaerobic gas mixture for 15 min prior to starting experiments. Oxygen levels were less than $0.3 \%$ in treated BSS as measured by a dissolved oxygen meter (Orion Model 830, Boston, MA, USA). Neuronal-glial cultures in 96-well microplates were transferred into the anaerobic chamber through an air lock and then washed seven times using Skan Washer 300 automated plate washer with deoxygenated BSS (greater than $2000 \times$ dilution). All drugs were resuspended in the smallest amount of solvent possible and then diluted with deoxygenated BSS in the chamber. Control cultures were treated with vehicle diluted in the same manner to control for residual oxygen in the solvent. After adding compounds to appropriate wells, cultures were placed in an incubator at $37^{\circ} \mathrm{C}$ within the chamber. After $30-105 \mathrm{~min}$, cultures were removed from the incubator and washed seven times with deoxygenated BSS and removed from the chamber. Reperfusion was performed by immediately adding an equal volume of oxygenated BSS supplemented with $5.5 \mathrm{mM}$ glucose, $1 \%$ antibiotic-antimycotic and vehicle or drug where appropriate. Cultures were then placed at $37^{\circ} \mathrm{C}$ for $24 \mathrm{~h}$ before cell death assessment by LDH release assay.

\section{Staurosporine and etoposide treatment}

Neuronal-glial cultures 17-20 DIV were treated with staurosporine or etoposide to induce apoptosis. Staurosporine (Sigma) was diluted to $214 \mu \mathrm{M}$ with dimethyl sulfoxide (DMSO; Sigma) and stored at $4^{\circ} \mathrm{C}$. Etoposide (Sigma) was diluted to $500 \mu \mathrm{M}$ with DMSO and stored at $-20^{\circ} \mathrm{C}$. Cultures were washed with BSS using an automated plate washer. An equal volume of BSS supplemented with $5.5 \mathrm{mM}$ glucose, $1 \%$ antibiotic-antimycotic, staurosporine or etoposide, and drug or vehicle was added to each well. Cultures were then returned to $37^{\circ} \mathrm{C}$ for $24 \mathrm{~h}$. After removal of two-thirds of the media for LDH release assay, some cultures were stained with Hoechst 33258 as described below.

\section{Cell death assessment}

Total cell death was estimated using LDH release, which has been widely used as a biochemical measure of cell injury. ${ }^{36-38}$ Briefly, $24 \mathrm{~h}$ after trauma, $75 \mu \mathrm{l}$ media was transferred to a 96-well microplate and diluted with $150 \mu \mathrm{L} \mathrm{LDH}$ assay reagent containing $5 \mathrm{mM} \beta$-NAD (Sigma), $25 \mathrm{mM}$ lactic acid (Sigma), $0.03 \%$ bovine serum albumin (BSA; Sigma), $100 \mathrm{mM}$ Trizma (Sigma) and $0.9 \% \mathrm{NaCl}(\mathrm{pH} \mathrm{8.45;}$ Sigma). Spectrophotometric analysis was performed at room temperature using a Ceres 900 microplate reader (Biotek Instruments, Inc., Winooski, VT, USA) measuring optical density at $340 \mathrm{~nm}$ over $250 \mathrm{~s}$ at $5 \mathrm{~s}$ intervals ( 50 readings per sample). Linear regression analysis provided an estimate of LDH activity. Basal LDH activity levels were subtracted from treatments prior to analysis.

\section{Hoechst 33258 staining}

Hoechst 33258 (Sigma) was diluted in deionized water to $10 \mathrm{mg} / \mathrm{ml}$ and stored at $-20^{\circ} \mathrm{C}$. Hoechst 33258 was added to culture media to a final concentration of $2 \mu \mathrm{g} / \mathrm{ml}$ and incubated at $37^{\circ} \mathrm{C}$ for $10 \mathrm{~min}$. Cultures were then washed with BSS and examined using a Nikon TE300 microscope (Nikon, Melville, NY, USA) with excitation at $360 \mathrm{~nm}$ and emission at $460 \mathrm{~nm}$. Images were captured using an Optronics DEI-750 digital camera (Optronics, Goleta, CA, USA) and Scion Image 1.62a software.

\section{Cell counts}

Counts of cells exhibiting nuclear morphology consistent with apoptosis was performed as previously described. ${ }^{39}$ Briefly, cultures were stained using Hoechst 33258 after treatment with staurosporine or etoposide in the presence or absence of DHPG as detailed above. Counts were performed at $400 \times$ using a Nikon TE300 microscope with excitation at $360 \mathrm{~nm}$ and emission at $460 \mathrm{~nm}$. A random field was selected for each culture and the number of cells containing condensed or fragmented nuclei were counted.

\section{Drugs}

(R,S)-1-aminoindan-1, 5-dicarboxylic acid (AIDA), (R,S)-2-chloro-5hydroxyphenylglycine (CHPG), (S)-4-carboxyphenylglycine (4CPG), dizocilpine (MK801), dihydroxyphenylglycine (DHPG), and -methyl-4carboxyphenylglycine (MCPG) were all purchased from Tocris Cookson.

\section{Acknowledgments}

This study was supported by a cooperative research agreement Department of Defense Grant (DAMD-17-93-V-3018) and Centers for Disease Control Grant R49 CCR306634-07.

\section{References}

1. Simon RP, Swan JH, Griffith T and Meldrum BS (1984) Blockade of N-methyl-Daspartate receptors may protect against ischemic damage in the brain. Science 226: 850-852

2. Faden Al and Simon RP (1988) A potential role for excitotoxins in the pathophysiology of spinal cord injury. Ann. Neurol. 23: 623-636

3. Faden AI, Demediuk P, Panter SS and Vink R(1989) The role of excitatory amino acids and NMDA receptors in traumatic brain injury. Science 244: 798-800

4. Kaku DA, Giffard RG and Choi DW (1993) Neuroprotective effects of glutamate antagonists and extracellular acidity. Science 260: 1516-1518

5. Mukhin AG, Ivanova SA, Knoblach SM and Faden AI (1997) New in vitro model of traumatic neuronal injury: evaluation of secondary injury and glutamate receptor mediated neurotoxicity. J. Neurotrauma 14:651-663

6. Gong Q-Z, Delahunty TM, Hamm RJ and Lyeth BG (1995) Metabotropic glutamate antagonist, MCPG, treatment of traumatic brain injury in rats. Brain Res. 700: 299-302

7. Mukhin AG, Fan L and Faden Al (1996) Activation of metabotropic glutamate receptor subtype mGluR1 contributes to post-traumatic neuronal injury. J. Neurosci. 16: 6012-6020 
8. Faden Al, Ivanova SA, Yakovlev AG and Mukhin AG (1998) Neuroprotective effects of group III mGluR in traumatic neuronal injury. J. Neurotrauma 14: 885 895

9. Allen JW, Ivanova SA, Fan L, Espey MG, Basile AS and Faden AI (1999) Group II metabotropic glutamate receptor activation attenuates traumatic neuronal injury and improves neurological recovery after traumatic brain injury. J. Pharmacol. Exp. Ther. 290: 112-120

10. Riedel G, Opitz T and Reymann KG (1996) Blockade of metabotropic glutamate receptors protects hippocampal neurons from hypoxia-induced cell death in rat in vivo. Prog. Neuropsychopharmacol. Biol. Psychiat. 20: 1253-1263

11. Opitz T, RichterRand Reymann KG(1994) The metabotropic glutamate receptor antagonist (+)-methyl-4-carboxyphenylglycine protects hippocampal CA1 neurons of the rat from in vitro hypoxia/hypoglycemia. Neuropharmacology 33: $715-717$

12. Buisson A and Choi DW (1995) The inhibitory mGluR agonist, s-4-carboxy-3 hydroxyphenylglycine selectively attenuates NMDA neurotoxicity and oxygenglucose deprivation-induced neuronal death. Neuropharmacology 34: 10811087

13. Pin J-P and Duvoisin R (1995) Review: neurotransmitter receptors I: the metabotropic glutamate receptors: structure and functions. Neuropharmacology 34: $1-26$

14. Bruno V, Copani A, KnopfelT, Kuhn R, Casabona G, Dell'Albani P, CondorelliDF and Nicoletti F (1995) Activation of metabotropic glutamate receptors coupled to inositol phospholipid hydrolysis amplifies NMDA-induced neuronal degeneration in cultured cortical cells. Neuropharmacology 34: 1089-1098

15. Copani A, Bruno VM, Barresi V, Battaglia G, Condorelli DF and Nicoletti F (1995) Activation of metabotropic glutamate receptors prevents neuronal apoptosis in culture. J. Neurochem. 64: 101-108

16. Copani A, Casabona G, Bruno V, Caruso A, Condorelli DF, Messina A, Di Giorg Gerevini V, Pin JP, Kuhn R, Knopfel T and Nicoletti F (1998) The metabotropic glutamate receptor mGlu5 controls the onset of developmental apoptosis in cultured cerebellar neurons. Eur. J. Neurosci. 10: 2173-2184

17. Copani A, Bruno V, Battaglia G, Leanza G, Pellitteri R, Russo A, Stanzani S and Nicoletti $F$ (1995) Activation of metabotropic glutamate receptors protects cultured neurons against apoptosis induced by $\beta$-amyloid peptide. Mol. Pharmacol. 47: 890-897

18. Maiese K and Vincent AM (1999) Group I metabotropic receptors down-regulate nitric oxide induced caspase-3 activity in rat hippocampal neurons. Neurosci. Lett. 264: 17-20

19. Vincent AM, TenBroeke M and Maiese K (1999) Metabotropic glutamate receptors prevent programmed cell death through the modulation of neuronal endonuclease activity and intracellular pH. Exp. Neurol. 155: 79-94

20. Koh JY, Wie MB, Gwag BJ, Sensi SL, Canzoniero LM, Demaro J, Csernansky C and Choi DW (1995) Staurosporine-induced neuronal apoptosis. Exp. Neurol. 135: $153-159$

21. Goldberg MP and Choi DW (1993) Combined oxygen and glucose deprivation in cortical cell culture: calcium-dependent and calcium-independent mechanisms of neuronal injury. J. Neurosci. 13: 3510-3524

22. Doherty AJ, Palmer MJ, Henley JM, Collingridge GL and Jane DE (1997) (RS)-2 chloro-5-hydroxyphenylglycine (CHPG) activates mGlu5, but not mGlu1, receptors expressed in $\mathrm{CHO}$ cells and potentiates NMDA responses in the hippocampus. Neuropharmacology 36: 265-267

23. Hayashi Y, Sekiyama N, Nakanishi S, Jane DE, Sunter DC, Birse EF, Udvarhely PM and Watkins JC (1994) Analysis of agonist and antagonist activities of phenylglycine derivatives for different cloned metabotropic glutamate receptor subtypes. J. Neurosci. 14: 3370-3377
24. Pellicciari R, Luneia R, Costantino G, Marinozzi M, Natalini $B$, Jakobsen $P$, Kanstrup A, Lombardi G, Moroni F and Thomsen C (1995) 1-Aminoindan-1,5dicarboxylic acid: a novel antagonist at phospholipase C-linked metabotropic glutamate receptors. J. Med. Chem. 38: 3717-3719

25. Moroni F, Lombardi G, Thomsen C, Leonardi P, Attucci S, Peruginelli F, Torregrossa SA, Pellegrini-Giampietro DE, Luneia R and Pellicciari R (1997) Pharmacological characterization of 1-aminoindan-1,5-dicarboxylic acid, a potent mGluR1 antagonist. J. Pharmacol. Exp. Ther. 281: 721-729

26. Ito I, Kohda A, Tanabe S, Hirose E, Hayashi M, Mitsunaga $S$ and Sugiyama $H$ (1992) 3,5-dihydroxyphenyl-glycine: a potent agonist of metabotropic glutamate receptors. Neuroreport 3: 1013-1016

27. Schoepp DD, Goldsworthy J, Johnson BG, Salhoff CR and Baker SR (1994) 3,5dihydroxyphenylglycine is a highly selective agonist for phosphoinositide-linked metabotropic glutamate receptors in the rat hippocampus. J. Neurochem. 63: $769-772$

28. Mukhin AG, Ivanova SA and Faden Al (1997) mGluR modulation of posttraumatic neuronal death: role of NMDA receptors. NeuroReport 8: 2561-2566

29. Allen JW, Eldadah BA and Faden Al (1999) Beta-amyloid-induced apoptosis of cerebellar granule cells and cortical neurons: exacerbation by selective inhibition of group I metabotropic glutamate receptors. Neuropharmacology 38: 12431252

30. Manzoni OJ, Poulat F, Do E, Sahuquet A, Sassetti I, Bockaert J and Sladeczek FA (1991) Pharmacological characterization of the quisqualate receptor coupled to phospholipase C (Qp) in striatal neurons. Eur. J. Pharmacol. Mol. Pharmacol. Sec. 207: 231-241

31. Yuzaki M and Mikoshiba K (1992) Pharmacological and immunocytochemical characterization of metabotropic glutamate receptors in cultured Purkinje cells. J. Neurosci. 12: 4253-4263

32. KohJ-Y and Cotman CW (1992) Programmed cell death: its possible contribution to neurotoxicity mediated by calcium channel antagonists. Brain Res. 587:233240

33. Johnson Jr EM and Deckwerth TL (1993) Molecular mechanisms of developmental neuronal death. Annu. Rev. Neurosci. 16: 31-46

34. Chavis P, Nooney JM, Bockaert J, Fagni L, Feltz A and Bossu J-L (1995) Facilitatory coupling between a glutamate metabotropic receptor and dihydropyridine-sensitive calcium channels in cultured cerebellar granule cells. J. Neurosci. 15: 135-143

35. Mukhin AG, Ivanova SI, Allen JW and Faden AI (1998) Mechanical injury to neuronal/glial cultures in microplates: role of NMDA receptors and $\mathrm{pH}$ in secondary neuronal cell death. J. Neurosci. Res. 51: 748-758

36. Koh J-Y and Choi DW (1987) Quantitative determination of glutamate mediated cortical neuronal injury in cell culture by lactate dehydrogenase efflux assay. J. Neurosci. Meth. 20: 83-90

37. Murphy EJ and Horrocks LA (1993) A model for compression trauma: pressureinduced injury in cell cultures. J. Neurotrauma 10: 431-444

38. Ellis EF, McKinney JS, Willoughby KA, Liang S and Povlishock JT (1995) A new model for rapid stretch-induced injury of cells in culture: characterization of the model using astrocytes. J. Neurotrauma 12: 325-339

39. Allen JW, Knoblach SM and Faden Al (1999) Combined mechanical trauma and metabolic impairment in vitro induces NMDA receptor-dependent neuronal cell death and caspase-3-dependent apoptosis. FASEB J. 13: 1875-1882 